\title{
Design, expression and characterization of a highly stable tetratricopeptide-based protein scaffold for phage display application
}

\author{
Edyta Petters ${ }^{1}$, Daniel Krowarsch ${ }^{2}$ and Jacek Otlewski ${ }^{1 凶}$ \\ 'Departament of Protein Engineering and 2Department of Protein Biotechnology, Faculty of Biotechnology, University of Wroclaw, Wrocław, \\ Poland
}

\begin{abstract}
Tetratricopeptide repeat (TPR) is a structural motif mediating variety of protein-protein interactions. It has a high potential to serve as a small, stable and robust, nonimmunoglobulin ligand binding scaffold. In this study, we showed the consensus approach to design the novel protein called designed tetratricopeptide repeat (dTPR), composed of three repeated 34 amino-acid tetratricopeptide motifs. The designed sequence was efficiently overexpressed in $E$. coli and purified to homogeneity. Recombinant dTPR is monomeric in solution and preserves its secondary structure within the $\mathrm{pH}$ range from 2.0 to 11.0. Its denaturation temperature at $\mathrm{pH} 7.5$ is extremely high $\left(104.5^{\circ} \mathrm{C}\right)$ as determined by differential scanning calorimetry. At extreme $\mathrm{pH}$ values the protein is still very stable: denaturation temperature is $90.1^{\circ} \mathrm{C}$ at $\mathrm{pH} 2.0$ and $60.4^{\circ} \mathrm{C}$ at $\mathrm{pH} 11$. Chemical unfolding of the dTPR is a cooperative, two-state process both at $\mathrm{pH} 7.5$ and 2.0. The free energy of denaturation in the absence of denaturant equals to $15.0 \mathrm{kcal} / \mathrm{mol}$ and $13.5 \mathrm{kcal} / \mathrm{mol}$ at $\mathrm{pH} 7.5$ and 2.0, respectively. Efficient expression and extraordinary biophysical properties make dTPR a promising framework for a biotechnological application, such as generation of specific ligand- binding molecules.
\end{abstract}

Key words: tetratricopeptide repeat; alternative scaffold; consensus design; protein stability

Received: 27 May, 2013; revised: 12 October, 2013; accepted: 12 November, 2013; available on-line: 17 December, 2013

\section{INTRODUCTION}

Engineered antibodies and their fragments for years have been the most successful and commonly used tools for biomolecular binding applications (Skerra, 2003). However, despite their undoubted merits, they remain rather difficult to obtain due to complicated molecular composition, posttranslational modifications and large size. Alternative protein scaffolds are a viable alternative to natural or recombinant antibodies (Skerra, 2007; Löfblom et al., 2011). Unlike to immunoglobulins, alternative scaffolds can be easily obtained in large quantities in inexpensive bacterial expression systems. However, one of the major challenges in design of such polypeptides is to engineer monomeric and highly stable scaffold. Increased stability of designed molecule is required to accommodate multiple substitutions, which are introduced to provide molecular interaction with defined target. Moreover, high stability ensures resistance to protease action and allows prolonged storage of such protein (Markert et al., 2001). Using phage, mRNA or yeast display polypeptide libraries based on designed stable scaffold can be subsequently used to select sequences, that recognize many molecular targets with high affinity and specificity (Binz et al., 2005).

Alternative scaffolds have been developed based on single structural domains or repeated polypeptide modules. The most successful examples of molecular binders based on single domain are: affibody (Löfblom et al., 2010), adnectin (Lipovsek et al., 2011), or anticalins (Skerra, 2008). The second large group of alternative scaffolds includes repetitive sequence motifs. These polypeptides are built of linearly arranged, small (typically 20-50 amino acids in length) structural motifs. Repetitive protein scaffolds have been already shown to successfully interact with proteins or peptides. Designed ankyrin repeat protein, binds HER2 with picomolar affinity (Zahnd et al., 2007), designed CTPR390+ protein containing three tetratricopeptide repeats interacts with the C-terminal peptide of Hsp90 with a $\mathrm{K}_{\mathrm{D}}$ of $1 \mu \mathrm{M}$ (Cortajarena et al., 2008), and designed armadillo repeat protein binds neurotensin with a $K_{D}$ of $7 \mu \mathrm{M}$ (Varadamsetty et al., 2012).

The tetratricopeptide repeat is a small, 34-amino acid, structural motif present in organisms from bacteria to humans (Sikorski et al., 1990). Proteins harboring repetitive TPR motifs mediate protein-protein interactions in a broad range of biochemical processes (D'Andrea \& Regan, 2003). Large diversity in molecular targets shows an enormous potential of the TPR motif to mediate specific and strong interactions with different ligands.

The number of repeats in TPR proteins varies from 3 to 16 . Three consecutive repeats are most commonly found, and represent the smallest possible number of TPR motifs capable of ligand binding. Almost all solved TPR structures possess an additional capping helix at C-terminus, which seems to be essential for the solubility and stability of the domain (D'Andrea \& Regan, 2003).

The TPR motifs are composed of helix-turn-helix elements, where $\alpha$-helices (termed A and B) are packed in anti-parallel fashion. Adjacent TPR motifs are parallel and adopt right-handed super-helical conformation, forming an amphipathic groove. The internal surface is formed mainly by the side-chains from helix A, whereas the opposite site of the protein contains amino acids from both helices A and B (D'Andrea \& Regan, 2003).

e-mail: otlewski@protein.pl

Abbreviations: TPR, tetratricopeptide repeat; dTPR, designed TPR protein containing three repeated TPR motifs; $C D$, circular dichroism; DSC, differential scanning calorimetry; $\mathrm{GdmCl}$, guanidine hydrochloride; TEV, tobacco etch virus 
Small size, repetitive nature, defined ligand binding area and highly degenerate sequence make TPR motif an interesting candidate for an alternative protein scaffold. In this paper we present the design, expression and biophysical characterization of a novel, extremely stable designed TPR (dTPR), which could serve as a molecular platform for combinatorial library selection.

\section{MATERIAL AND METHODS}

Design of the TPR consensus sequence and structure modeling. We collected 413 TPR sequences from SMART database (Schultz et al., 1998) and aligned them with ClustalW (Larkin et al., 2007). Amino acid frequency at all positions were calculated. The protein model was built using crystal structure of CTPR3 as a template (PDB ID: 1NA0) with Swiss-Model sever (Arnold et al., 2006).

Cloning and molecular biology. dTPR sequence (containing three repeated TPR motifs with $\mathrm{N}$-capping sequence and solvating helix at the C-terminus) was optimized for E. coli expression, synthesized and cloned into pPCR_Script vector by Sloning Bio'Technology (Germany). At the N-terminal sequence of dTPR we added a cleavage sequence for TEV (tobacco etch virus) protease: NLYFQGSS. Recombination sites (attB) for the Gateway cloning system were added on both sides of the gene. dTPR was cloned to pDONR201 vector in Gateway BP reaction, and subsequently into the destination vector pDST15 in Gateway LR reaction.

Expression and purification of dTPR. E. coli BL21 (DE3) RIL strain was transformed with the pDST15 vector containing dTPR. Colonies were selected on LB-agar plates containing $34 \mu \mathrm{g} / \mathrm{ml}$ chloramphenicol and 100 $\mu \mathrm{g} / \mathrm{ml}$ ampicillin. Transformants were grown in $200 \mathrm{ml}$ of LB medium $(100 \mu \mathrm{g} / \mathrm{ml}$ of ampicillin and $34 \mu \mathrm{g} / \mathrm{ml}$ chloramphenicol) overnight at $37^{\circ} \mathrm{C}, 200 \mathrm{rpm}$, then 25 $\mathrm{ml}$ of the overnight culture was transferred to 11 of LB medium and grown as above to an $\mathrm{OD}_{600}$ of 0.8 . Protein expression was induced with isopropyl $\beta$-D-1-thiogalactopyranoside (IPTG) added to $0.6 \mathrm{mM}$ and the bacteria were further cultivated overnight at $27^{\circ} \mathrm{C}$. Cells were harvested by centrifugation $\left(4^{\circ} \mathrm{C}, 3300 \times g, 8 \mathrm{~min}\right)$, pellet from $4 \mathrm{l}$ of culture was resuspended in $80 \mathrm{ml}$ of ice-cold lysis buffer $(150 \mathrm{mM} \mathrm{NaCl}, 5 \mathrm{mM}$ EDTA, $50 \mathrm{mM}$ Tris$\mathrm{HCl}, \mathrm{pH} 8.0$ ), sonicated and centrifuged at $14500 \times \mathrm{g}$ for 1 hour at $4^{\circ} \mathrm{C}$. The supernatant was applied on Glutathione Sepharose column for $1.5 \mathrm{~h}$ at $4^{\circ} \mathrm{C}$, and the resin was washed with 21 of washing buffer $(250 \mathrm{mM} \mathrm{NaCl}$, $2.5 \mathrm{mM}$ EDTA, $50 \mathrm{mM}$ Tris-HCl, $\mathrm{pH}$ 8.0). Bound proteins were eluted with $60 \mathrm{ml}$ of $100 \mathrm{mM} \mathrm{NaCl}, 25 \mathrm{mM}$ reduced glutathione, $25 \mathrm{mM}$ Tris, $\mathrm{pH} 8.0$ and analyzed by $12 \%$ SDS-PAGE gel. Fractions with the highest protein concentration were pooled and GST-tag was cleaved with TEV protease $\left(4^{\circ} \mathrm{C}, 48 \mathrm{~h}\right)$. dTPR was separated from GST-tag on Glutathione Sepharose. Concentrated dTPR was applied on Superdex 75 prep-grade column (GE Healthcare) equilibrated with $100 \mathrm{mM} \mathrm{NaCl}$, $50 \mathrm{mM}$ phosphate, $\mathrm{pH} 6.3$ and eluted at $1 \mathrm{ml} / \mathrm{min}$ at $4^{\circ} \mathrm{C}$. The homogeneity of the purified protein was analyzed by Superdex 75 analytical column (GE Healthcare). Protein identity was assessed with AB 4800+ MALDI TOF/TOF (Applied Biosystems) mass spectrometer.

Circular dichroism (CD) measurements. CD spectra were acquired on a Jasco J-715 spectropolarimeter in a $1 \mathrm{~mm}$ cuvette with the dTPR concentration of $1.4 \times 10^{-5} \mathrm{M}$ at $21^{\circ} \mathrm{C}$ that allowed us to measure good quality CD spectra within the range of 195 to 265 $\mathrm{nm}$. The protein was dialyzed to the following buffers: $5 \mathrm{mM}$ glycine at $\mathrm{pH}$ between 2.0 and $3.0,5 \mathrm{mM}$ citrate, $\mathrm{pH} 4.0$, or $10 \mathrm{mM}$ sodium phosphate at $\mathrm{pH}$ between 5.0 and 12.0. Spectra were averaged from three separate scans with a slit width set to $2 \mathrm{~nm}$ and a response time of 1 s. Estimation of a secondary structure content was performed with K2D2 software (Perz-Iratxeta \& Andrade-Navarro, 2008).

CD-monitored thermal denaturation was carried out in $5 \mathrm{mM}$ glycine, $\mathrm{pH} 2.0$ and 3.0 or in $10 \mathrm{mM}$ sodium phosphate, $\mathrm{pH} 10.0$ or 11.0 with the protein concentration of $3.6 \times 10^{-6} \mathrm{M}$. Thermal scans were performed in a $1 \mathrm{~cm}$ cuvette following ellipticity at $222 \mathrm{~nm}$ using a response time of $16 \mathrm{~s}$. An automatic Peltier accessory PFD $350 \mathrm{~S}$ allowed continuous monitoring of the thermal transition at a constant rate of $1{ }^{\circ} \mathrm{C} / \mathrm{min}$. The data were analyzed using PeakFit software (Jandel Scientific Software) assuming a two-state reversible equilibrium transition as described previously (Zakrzewska et al., 2005).

Chemical denaturation of dTPR with guanidine chloride $(\mathrm{GdmCl})$ was monitored with a Jasco J-715 spectropolarimeter at $21^{\circ} \mathrm{C}$. Protein samples were incubated with a various concentrations of $\mathrm{GdmCl}$ in $10 \mathrm{mM}$ Tris $\mathrm{pH} 7.5$ or $10 \mathrm{mM}$ glycine 2.0 for $24 \mathrm{~h}$ at $21^{\circ} \mathrm{C}$. To ensure an adequate signal-to-nose ratio we used protein concentration of $3.6 \times 10^{-6} \mathrm{M}$. The transitions were monitored by the changes of the CD signal at $222 \mathrm{~nm}$ with a $2 \mathrm{~nm}$ bandwidth. The free energy change of denaturation in the absence of denaturant $\left(\Delta \mathrm{G}_{\mathrm{H} 2 \mathrm{O}}\right)$ was determined by fitting $\mathrm{CD}$ intensity changes as a function of $\mathrm{GdmCl}$ concentration, as described previously (Wezner-Ptasińska et al., 2011).

Differential scanning calorimetry (DSC) measurements. DSC experiments were performed on a Nano DSC II (Calorimetry Sciences Corp.) in the temperature range from 25 to $125^{\circ} \mathrm{C}$ at $7.16 \times 10^{-5} \mathrm{M}$ protein concentration (total cell volume $323 \mu \mathrm{l}$ ). The scan rate was $1.0^{\circ} \mathrm{C} / \mathrm{min}$ under pressure excess of $2.5 \mathrm{~atm}$. Combination of appropriate protein concentration and scan rate allowed us to determine a reversible, two state dTPR denaturation. Before DSC run protein was extensively dialyzed against $10 \mathrm{mM}$ Gly-Gly buffer, pH 7.5. Baseline was determined by running the calorimeter with both cells filled with the dialysis buffer. Reversibility of denaturation was checked through repeated heating of the protein sample. Denaturation parameters were calculated from thermogram analysis using CpCalc software (Calorimetry Sciences Corp.).

\section{RESULTS AND DISCUSSION}

\section{Design of TPR scaffold}

In order to produce a folded and stable protein based on a TPR motif, we applied a method that combines consensus sequence design (Steipe et al., 1994) with protein charge neutralization (Cortajarena et al., 2004). We have successfully applied this approach to design stable scaffold based on leucine-reach repeat (Wezner-Ptasińska et al., 2011) as well as to increase protein stability (Zakrzewska et al., 2005). Proteins based on idealized TPR motif were previously designed by Regan group (Main et al., 2003) and the approach was based on statistical analysis of TPR sequences in the Pfam database. For each position in the TPR motif ratio of the percentage of occurrence of an amino acid at a given position to its percentage occurrence within the TPR sequences (parameter called global propensity) was calculated. Res- 


\section{A}
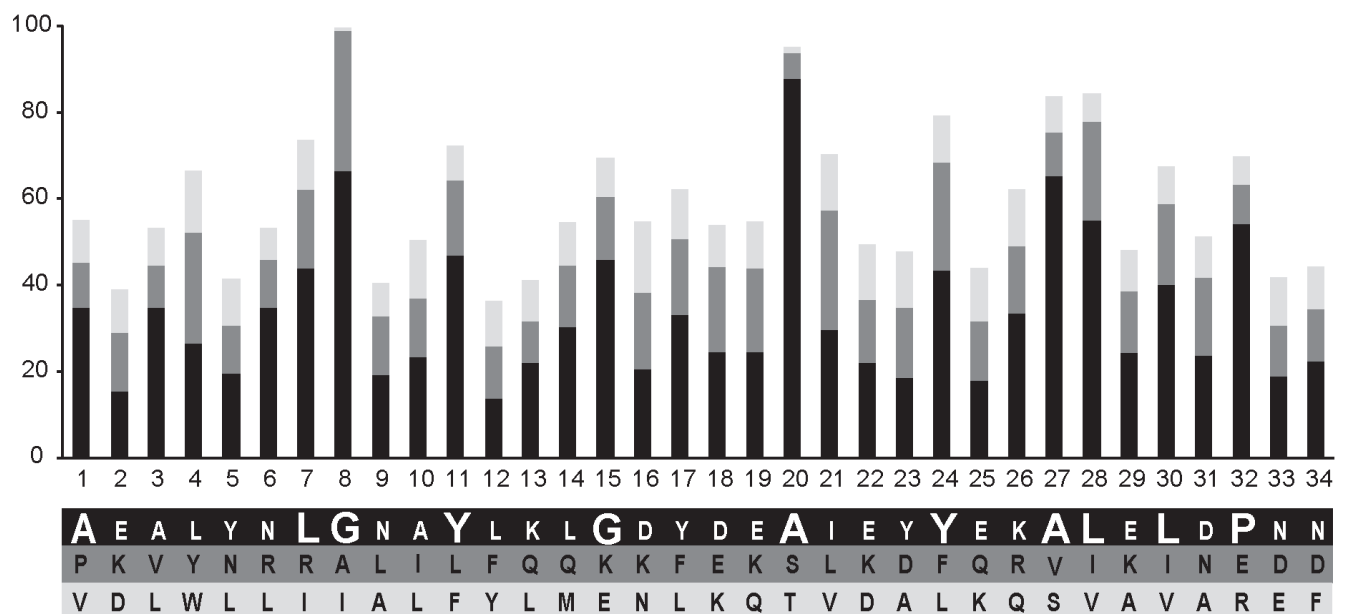

B A E A W Y N L G N A Y Y K Q G D Y D E A I E Y Y Q K A L E L D P N N

C

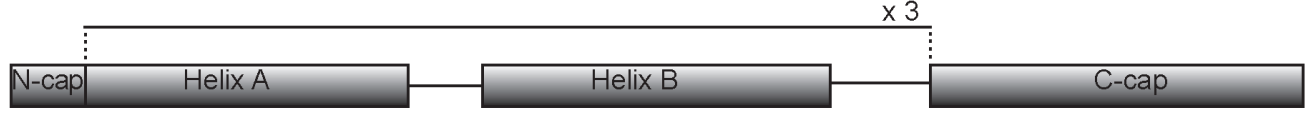

$\mathrm{D}$

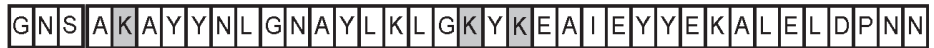

A E A Y Y Y N L G G A Y Y L KL L G K Y K KE A I E E Y Y Y E K A L LELLDPN N

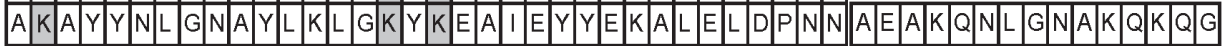

12345678910111213141516171819202122232425262728293031323334

$E$
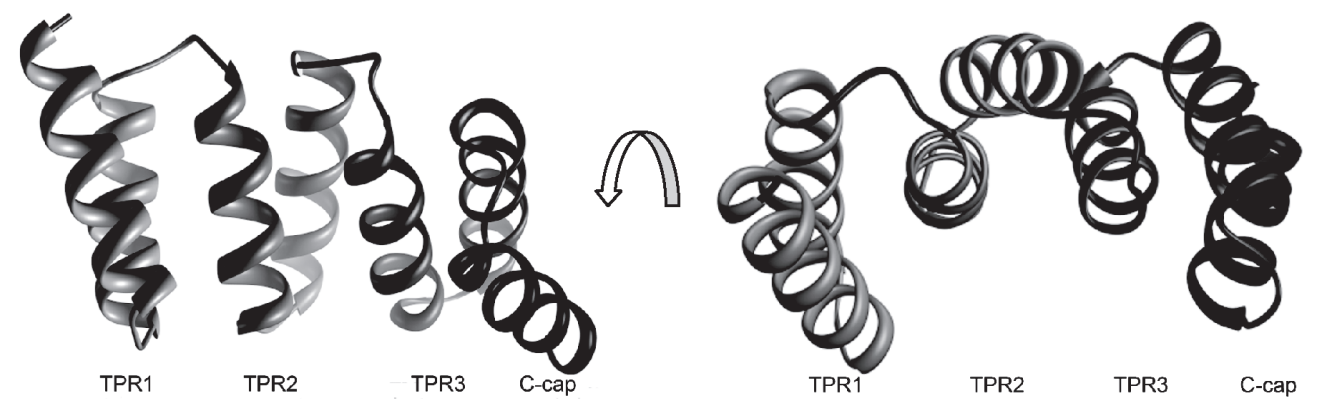

Figure 1. Design of the dTPR sequence.

(A) Histogram representation of amino acids frequency of three most populated amino acids at given position of TPR. First line lower panel shows consensus sequence of TPR, amino acids with occurrence over $40 \%$ are enlarged. (B) Sequence of the TPR motif designed by Main et al. (2003). (C) Schematic presentation of dTPR secondary structure. (D) Amino acid sequence of charge-modified dTPR motif. Changes incorporated to the consensus sequence are shaded in grey. (E) dTPR model based on the crystal structure of CTPR3 (PDB ID: 1NAO).

idues with the highest global propensity were placed at given position of the designed TPR motif.

In our study, consensus sequence of the TPR motif was based on sequences collected from the SMART database. Family of 413 non redundant amino acid sequences of TPR motif were aligned with ClustalW, and amino acid frequencies at a particular position were calculated. The most frequent amino acids were used to define the 34 amino acids sequence of TPR (Fig. 1A).

The strongest preference $(>40 \%$ occurrence of a particular amino acid at a given position) was observed at 10 positions: $7,8,11$ in helix $A, 20,24,27,28,30$ in helix B, 15 and 32 in turns between helices (Fig. 1A). Compared to the sequence of idealized TPR motif (Main et al., 2003) we observed four amino acid sequence differences (Fig 1A, B). At positions 4 and 12 and 14 the most frequently occurring amino acid according to our analysis was leucine instead of, respectively: tryptophan, tyrosine and methionine. At position 25 we identified glutamate instead of previously reported glutamine (Main et al., 2003). Since we found almost the same percentage occurrence of leucine $(26.39 \%)$ and tyrosine $(25.91 \%)$ at position 4, we introduced tyrosine, expecting that hydroxyl group of the side chain could form additional hydrogen bond with surrounding residues stabilizing the protein conformation.

Since three arrayed TPRs are mostly observed in proteins and probably represent the minimal number of TPR domains required for ligand binding (D'Andrea \& Regan, 2003), we constructed dTPR protein containing three repeated motifs. To increase the stability and solubility of the designed protein, we added N-capping sequence (GNS-) and solvating helix (-AEAKQNLGNAKQKQG) at the C-terminus of arrayed TPRs, as previously reported by Main et al. (2003) (Fig. 1D, E).

As the final step in the design of dTPR, we modified the charge of the protein. The net charge of natural TPRs tends to be near zero. It was also shown, that charge neutralization of designed TPR polypeptide increased the protein stability (Cortajarena et al., 2004). 
A

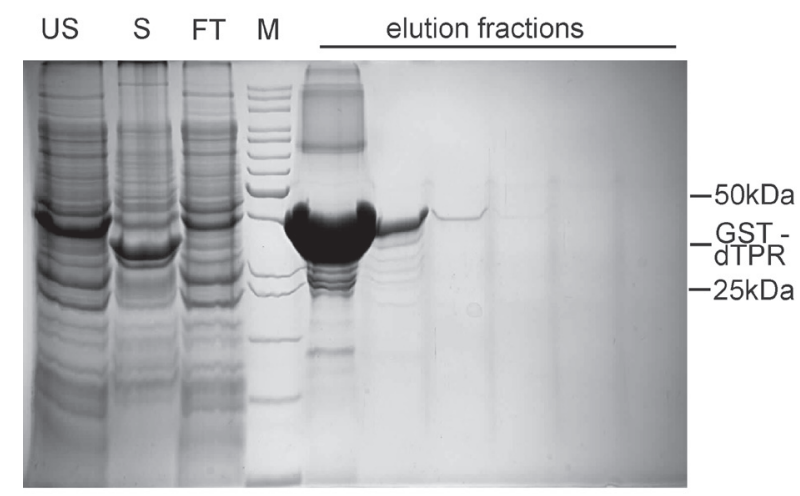

B

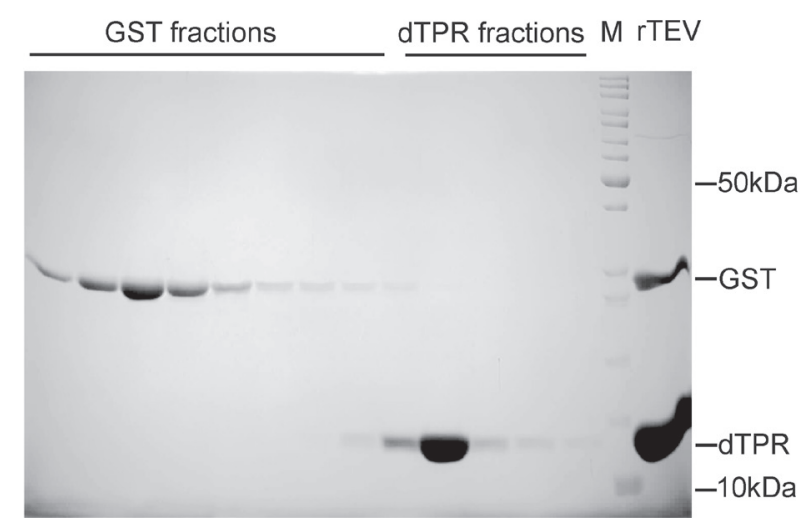

Figure 2. Electrophoretic analysis of dTPR purification.

Fractions eluted from Glutathione Sepharose resin (A) or Superdex 75 (B) are shown, I - insoluble fraction, S - soluble fraction, FT - flow through fraction after binding to glutathione resin, $M$ molecular weight marker, rTEV - cleavage of dTPR-GST-tag fusion protein.

Within the sequence of designed TPR motif, we noticed eight negatively charged amino acids $(5 \times$ Glu and $3 \times$ Asp) and two positively charged lysines (Fig 1A). The theoretical net charge at neutral $\mathrm{pH}$ of the construct composed of three TPR repeats, $\mathrm{N}$-capping sequence and solvating helix is equal to -16 . To neutralize the net charge of designed TPR we substituted selected glutamates or aspartates with lysines. We located these electrostatic substitutions outside the ligand binding surface: at positions 16 and 18 in all three TPR motifs we introduced lysine instead of aspartic acid and at position 2 in TPR motifs 1 and 3 we placed lysine instead of glutamic acid. The total net charge of final dTPR construct was zero.

The dTPR protein sequence differs at 20 positions as compared to the sequence designed by Main et al. (2003) or at 28 positions as compared to the charge modified TPR presented by (Cortajarena et al., 2004).

\section{Expression and purification of dTPR}

dTPR was overexpressed as a GST-tag fusion in E. coli BL21 (DE3) RIL strain. The highest protein expression yield was observed after $16 \mathrm{~h}$ incubation at $27^{\circ} \mathrm{C}$ upon induction with $0.6 \mathrm{mM}$ IPTG. Protein purification was performed based on affinity and size exclusion chromatography (Fig. 2A, B). The yield was about $10 \mathrm{mg}$ of purified protein per 11 of culture. The homogeneity of
Table 1. Thermodynamic parameters for the thermal denaturation of dTPR calculated from CD experiments.

\begin{tabular}{lll}
\hline $\mathrm{pH}$ & $\mathrm{T}_{\text {den }}\left({ }^{\circ} \mathrm{C}\right)$ & $\Delta H_{\mathrm{vH}}(\mathrm{kcal} / \mathrm{mole})$ \\
\hline $\mathrm{pH} 2.0$ & 90.1 & 104.5 \\
\hline $\mathrm{pH} 3.0$ & 92.7 & 100.2 \\
\hline $\mathrm{pH} 10.0$ & 87.8 & 113.3 \\
\hline $\mathrm{pH} 11.0$ & 60.4 & 84.5 \\
\hline
\end{tabular}

The standard errors in $\mathrm{T}_{\text {den }}$ and $\Delta H_{\mathrm{vH}}$ were estimated to be: $\pm 0.1^{\circ} \mathrm{C}$ and $\pm 5.0 \mathrm{kcal} / \mathrm{mol}$, respectively.

dTPR was confirmed by size-exclusion chromatography on analytical Superdex 75. A single peak was observed indicating monomeric state of recombinant dTPR protein (data not shown). Molecular weight of protein (including sequence GNS-located at the N-terminal site and remained after cloning) was determined using mass spectrometer to be $13934.24 \mathrm{Da}$, which is consistent with MW calculated from amino acid sequence (13935.32 Da).

\section{Biophysical properties}

Conformation of dTPR protein (containing three repeated TPR motifs with N-capping sequence and solvating helix at the $\mathrm{C}$-terminus) was analyzed by circular dichroism (CD) measurements. Far-UV spectra of the designed protein showed high helical content (Fig. 3A) with typical minima at 208 and $220 \mathrm{~nm}$ and maximum at $190 \mathrm{~nm}$. CD spectra analysis with K2D2 software revealed $84 \%$ of a-helix. We also collected CD spectra of dTPR at various pHs. Even at pHs 2.0 and 11.0 the shape of $\mathrm{CD}$ spectrum is very similar to that at $\mathrm{pH} 7.0$ (Fig. 3A) showing that the protein is extremely $\mathrm{pH}$ resistant.

The conformational stability of dTPR was analyzed by thermal and chemical denaturation. Using CD spectroscopy, we observed highly cooperative and reversible unfolding transitions at $\mathrm{pHs} 2.0,3.0,10.0$ and 11.0 (Fig. 3B, Table 1). The denaturation transition at $\mathrm{pH}$ 7.5 could not be monitored by $\mathrm{CD}$ as the transition exceeded $100^{\circ} \mathrm{C}$. The lowest stability, with a midpoint of $60.4^{\circ} \mathrm{C}$ was observed at $\mathrm{pH} 11.0$ (Table 1 ).

We also determined the denaturation parameters of the dTPR using DSC (Fig. 3C). The thermodynamic values calculated from thermogram showed denaturation temperature $104.5^{\circ} \mathrm{C}$, calorimetric enthalpy $\left(\Delta H_{\text {cal }}\right)$ equal to $122.1 \mathrm{kcal} / \mathrm{mol}$ and van't Hoff enthalpy $\left(\Delta H_{\mathrm{vH}}\right)$ $120.8 \mathrm{kcal} / \mathrm{mol}$. Very close values of calorimetric and van't Hoff enthalpy indicate a two-state mechanism of denaturation of the dTPR (Privalov, 1979). Additionally, heat capacity change $\left(\Delta C_{\text {pden }}\right)$ was calculated directly from thermogram to be $0.85 \mathrm{kcal} / \mathrm{molK}$. The denaturation parameters allowed us to calculate the free energy change of denaturation $\Delta G_{\text {den }}(\mathrm{T})$ from the GibbsHelmholtz equation: $\Delta G_{\text {den }}(\mathrm{T}) \stackrel{\text { den }}{=} \Delta H_{\mathrm{vH}}\left(1-\mathrm{T} / \mathrm{T}_{\mathrm{den}}\right)-$ $\Delta C_{\mathrm{p} \text { den }}\left[\left(\mathrm{T}_{\mathrm{den}}-\mathrm{T}\right)+\mathrm{T} \ln \left(\mathrm{T} / \mathrm{T}_{\mathrm{den}}\right)\right]$ (Becktel \& Schellman, 1987). The calculated value of $\Delta G_{\text {den }}$ at $21^{\circ} \mathrm{C}$ equals to $18.1 \mathrm{kcal} / \mathrm{mol}$ that is extremely high, compared to many naturally occurring proteins (Makhatadze \& Privalov, 1995).

In the next step of thermodynamic stability analysis of TPR, we performed chemical denaturation using $\mathrm{GdmCl}$ (Fig. 3D). We found that the protein is very resistant to denaturant, and the free energy change of denaturation in the absence of denaturant $\left(\Delta G_{\mathrm{H} 2 \mathrm{O}}\right)$ equals to $15 \mathrm{kcal} /$ 
A

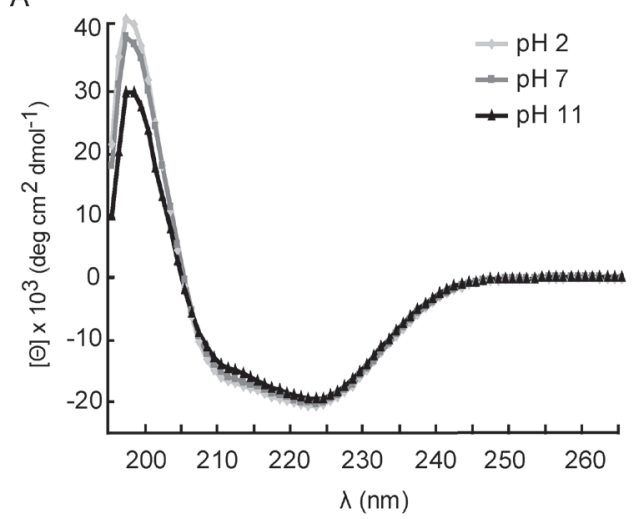

C

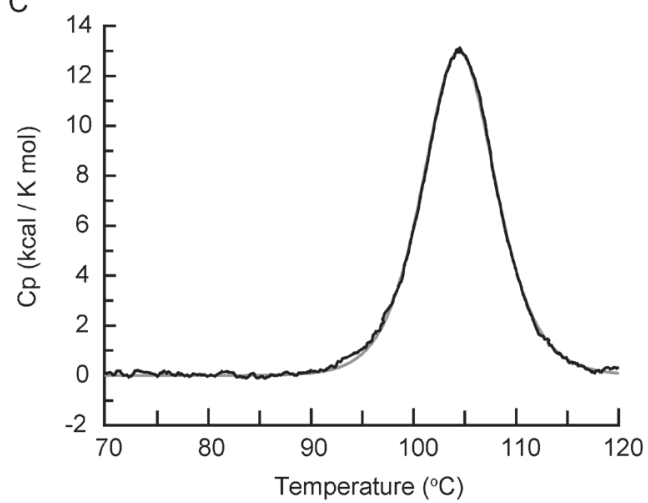

B

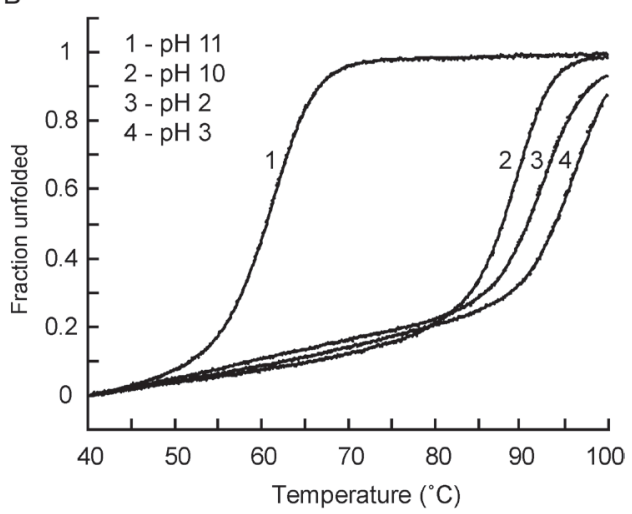

D

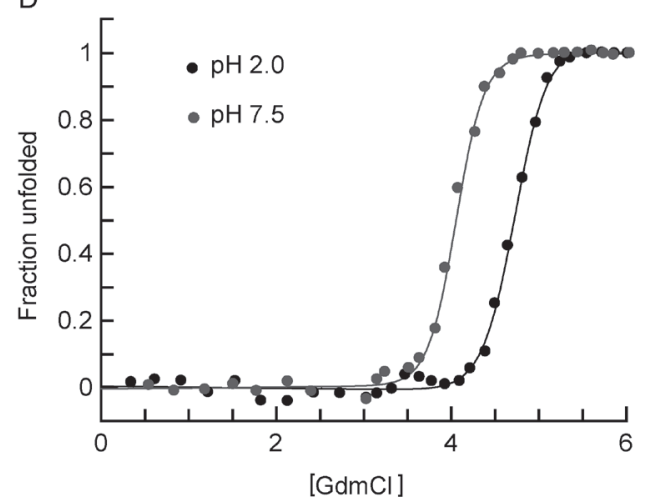

Figure 3. Biophysical studies of the dTPR.

(A) Far-UV CD spectra of dTPR at different pH conditions: pH 2.0 (light grey line), 7.0 (grey line) and 11.0 (black line). (B) Thermal denaturation monitored by ellipticity changes at $222 \mathrm{~nm}$. (C) Temperature dependence of the partial molar heat capacity of dTPR. The best approximation using a two-state equation is depicted by grey continuous line. (D) Chemical unfolding at increasing $\mathrm{GdmCl}$ concentrations determined at $\mathrm{pH} 2.0$ and 7.5 .

mol at $\mathrm{pH} 7.5$, concentration of $\mathrm{GdmCl}$ at midpoint was 4.05 and $\mathrm{m}$ value equals to $3.7 \mathrm{kcal} / \mathrm{mol} \mathrm{M}$. Taking into account different methods of denaturation and long extrapolation of experimental data, we conclude that both DSC and chemical denaturation provide coherent values of free energy change of denaturation at $\mathrm{pH}$ 7.5. Compared to $\mathrm{pH} 7.5$, the $\Delta G_{\mathrm{H} 2 \mathrm{O}}$ at $\mathrm{pH} 2.0$ was lower only by $1.5 \mathrm{kcal} / \mathrm{mol}$, concentration of $\mathrm{GdmCl}$ at midpoint was $4.73 \mathrm{M}$ and $\mathrm{m}$ value $=2.85 \mathrm{kcal} / \mathrm{mol} \mathrm{M}$.

Compared with other tetratricopeptide repeat proteins the dTPR is significantly more stable. The TPR domains of natural proteins e.g: TPR domain of PP5, TPR1 of Hop, TPR2A of Hop or 3-TPR of Vpu binding protein, show $\mathrm{T}_{\text {den }}$ about $50^{\circ} \mathrm{C}$ (Cortajarena \& Regan, 2006). The CTPR3 protein (containing three TPR repeats) obtained in Regan laboratory has $\mathrm{T}_{\text {den }}$ lower by $21.5^{\circ} \mathrm{C}$ at $\mathrm{pH} 6.3$,

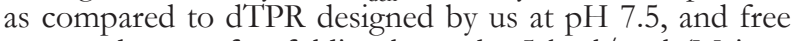
energy change of unfolding lower by $5 \mathrm{kcal} / \mathrm{mol}$ (Main et al., 2003). The modified sequence of CTPR3 designed to bind Hsp90 that was "charge neutralized" (Cortajarena et al., 2004) was still at least $10^{\circ} \mathrm{C}$ or $3 \mathrm{kcal} / \mathrm{mol}$ less stable than our dTPR. Comparison to other designed repeated proteins the dTPR shows favorable thermodynamic properties. Highly stable variant of armadillo repeat protein shows $\mathrm{T}_{\mathrm{den}}=85.5^{\circ} \mathrm{C}$ (Alfarano et al., 2012), proteins containing three ankyrin repeats selected from combinatorial library (variant E3_5) or designed by full consensus approach (NI3C) denature above $90^{\circ} \mathrm{C}$ or even above $100^{\circ} \mathrm{C}$ respectively (Binz et al., 2003; Wetzel et al., 2008). Finally, a stable scaffold based on six leucine-rich repeats (dVLR), that we designed previously shows $\mathrm{T}_{\text {den }}$ $=73.9^{\circ} \mathrm{C}$ at $\mathrm{pH} 6.0$ (Wezner-Ptasińska et al., 2011).

Favorable biophysical properties of dTPR protein may provide substantial advantage in terms of generation of specific ligand-binding molecules. Stable scaffold could accommodate a number of mutations providing interaction with defined ligand, and still preserve its structural stability.

\section{Acknowledgments}

The work was supported by the Wroclaw Research Center EIT + under the project "Biotechnologies and advanced medical technologies - BioMed" (POIG 01.01.02-02-003/08/00) financed by the European Regional Development Fund (Operational Program Innovative Economy, 1.1.2)

\section{REFERENCES}

Alfarano P, Varadamsetty G, Ewald C, Parmeggiani F, Pellarin R, Zerbe O, Plückthun A, Caflisch A (2012) Optimization of designed armadillo repeat proteins by molecular dynamics simulations and NMR spectroscopy. Protein Sci 21: 1298-1314.

Arnold K, Bordoli L, Kopp J, Schwede T (2006) The SWISS-MODEL Workspace: A web-based environment for protein structure homology modelling. Bioinformatics 22: 195-201.

Becktel WJ, Schellman JA (1987) Protein stability curves. Biopolymers 26: 1859-1877.

Binz HK, Amstutz P, Plückthun A (2005) Engineering novel binding proteins from nonimmunoglobulin domains. Nat Biotechnol 23: 1257-1268.

Binz HK, Stumpp MT, Forrer P, Amstutz P, Plückthun A (2003) Designing repeat proteins: well-expressed, soluble and stable proteins 
from combinatorial libraries of consensus ankyrin repeat proteins. $J$ Mol Biol 332: 489-503.

Cortajarena AL, Kajander T, Pan W, Cocco MJ, Regan L (2004) Protein design to understand peptide ligand recognition by tetratricopeptide repeat proteins. Protein Eng Des Sel 17: 399-409.

Cortajarena AL, Regan L (2006) Ligand binding by TPR domains. Protein Sci 15: 1193-1198.

Cortajarena AL., Yi F, Regan L (2008) Designed TPR modules as novel anticancer agents. ACS Chem Biol 3: 161-166.

D'Andrea LD, Regan L (2003) TPR proteins: the versatile helix. Trends Biochem Sci 28: 655-662.

Larkin MA, Blackshields G, Brown NP, Chenna R, McGettigan PA, McWilliam H, Valentin F, Wallace IM, Wilm A, Lopez R, Thompson JD, Gibson TJ, Higgins DG (2007) ClustalW and ClustalX version 2. Bioinformatics 23: 2947-2948.

Lipovsek D (2011) Adnectins: engineered target-binding protein therapeutics. Protein Eng Des Sel 24: 3-9.

Löfblom J, Feldwisch J, Tolmachev V, Carlsson J, Ståhl S, Frejd FY (2010) Affibody molecules: engineered proteins for therapeutic, diagnostic and biotechnological applications. FEBS Lett 584: 26702680.

Löfblom J, Frejd FY, Ståhl S (2011) Non-immunoglobulin based protein scaffolds. Curr Opin Biotechnol 22: 843-838.

Main ER, Xiong Y, Cocco MJ, D’Andrea L, Regan L (2003) Design of stable alpha-helical arrays from an idealized TPR motif. Structure 11: $497-508$

Makhatadze GI, Privalov PL (1995) Energetics of protein structure. Adv Protein Chem 47: 307-425.

Markert Y, Köditz J, Mansfeld J, Arnold U, Ulbrich-Hofmann R (2001) Increased proteolytic resistance of ribonuclease $A$ by protein engineering. Protein Eng 14: 791-796.

Perz-Iratxeta C, Andrade-Navarro MA (2008) K2D2: estimation of protein secondary structure from circular dichroism spectra. BMC Struct Biol 8: 25.

Privalov PL (1979) Stability of proteins: small globular proteins. $A d v$ Protein Chem 33: 167-241.
Schultz J, Milpetz F, Bork P, Ponting CP (1998) SMART, a simple modular architecture research tool: identification of signaling domains. Proc Natl Acad Sci USA 95: 5857-5864.

Sikorski RS, Boguski MS, Goebl M, Hieter P (1990) A repeating amino acid motif in CDC23 defines a family of proteins and a new relationship among genes required for mitosis and RNA synthesis. Cell 60: $307-317$.

Skerra A (2003) Imitating the humoral immune response. Curr Opin Chem Biol 7: 683-693.

Skerra A (2007) Alternative non-antibody scaffolds for molecular recognition. Curr Opin Biotechnol 18: 295-304.

Skerra A (2008) Alternative binding proteins: anticalins - harnessing the structural plasticity of the lipocalin ligand pocket to engineer novel binding activities. FEBS J 275: 2677-2683.

Steipe B, Schiller B, Pluckthun A, Steinbacher S (1994) Sequence statistics reliably predict stabilizing mutations in a protein domain. $J \mathrm{Mol}$ Biol 240: 188-192.

Varadamsetty G, Tremmel D, Hansen S, Parmeggiani F, Plückthun A (2012) Designed armadillo repeat proteins: library generation, characterization and selection of peptide binders with high specificity. $J$ Mol Biol 424: 68-87.

Wetzel SK, Settanni G, Kenig M, Binz HK, Plückthun A (2008) Folding and unfolding mechanism of highly stable full-consensus ankyrin repeat proteins. J Mol Biol 376: 241-257.

Wezner-Ptasińska M, Krowarsch D, Otlewski J (2011) Design and characteristics of a stable protein scaffold for specific binding based on variable lymphocyte receptor sequences. Biochim Biophys Acta 1814: 1140-1145.

Zahnd E, Wyler JM, Schwenk D, Steiner MC, Lawrence NM, McKern F, Pecorari CW, Ward TO, Joos A, Plückthun A (2007) Designed Ankyrin Repeat Protein Evolved to Picomolar Affinity to Her2. J Mol Biol 369: 1015-1028.

Zakrzewska M, Krowarsch D, Wiedlocha A, Olsnes S, Otlewski J (2005) Highly stable mutants of human fibroblast growth factor-1 exhibit prolonged biological action. J Mol Biol 352: 860-875. 